\title{
KVALITETA SJEMENA TRADICIJSKIH CVJETNIH VRSTA ZA AMATERSKI UZGOJ
}

\author{
Dijana HORVAT ${ }^{1}$, Vesna ŽIDOVEC ${ }^{2}$, S. MARCIJUŠ ${ }^{1}$ \\ ${ }^{1}$ Visoko gospodarsko učilište u Križevcima \\ College of agriculture at Križevci \\ ${ }^{2}$ Agronomski fakultet Sveučilišta u Zagrebu \\ Faculty of Agriculture, University of Zagreb
}

\begin{abstract}
SAŽETAK
Tradicijske cvjetne vrste uz povrtne, aromatične i ljekovite biljke bile su važni stanovnici tradicijskih seoskih vrtova. Tijekom 20. stoljeća, promjenom životnih navika seoskog stanovništava, počinje izumiranje tradicijskih seoskih vrtova a s njima i tradicijskih cvjetnih vrsta. Danas vrtlari amateri pokušavaju obnoviti tradicijske seoske vrtove no najčešći rezultat su vrtovi bogati cvjetnim vrstama koje susrećemo u ponudi velikih trgovačkih lanaca, u maloprodaji i na tržnicama.

Loša kvaliteta sjemena mogući je uzrok nestajanja tradicijskih cvjetnih vrsta. Proizvodnje sjemena cvjetnih vrsta u Hrvatskoj nema, ponuda je bazirana na uvozu sjemena čija kvaliteta prema Pravilniku o stavljanju na tržište poljoprivrednog reprodukcijskog materijala ukrasnog bilja NN 129/07 ne podliježe nikakvoj kontroli. Na 18 uzoraka sjemena deset cvjetnih vrsta uvezenih 2011/12: Ageratum hosutonianum, Calistephus chinensis, Cosmos bipinatus, Dahlia pinata, Impatiens walleriana, Lavandula officinalis, Lobelia erenis, Tagetes patula, Verbrena $\times$ hybrida, Zinia elegans ispitana je energija klijanja, klijavost i zdravstveno stanje sjemena, prema ISTA međunarodnim metodama ispitivanja. Ispitivani uzorak je osim tradiconalnih cvjetnih vrsta obuhvatio i nekoliko komercijalnih cvjetnih vrsta. Nicanje u kontejnerima, rast u cvjetnim posudama i boja cvjetova ispitivani su na osam cvjetnih vrsta: Ageratum hosutonianum, Dahlia - mini, Impatiens walleriana, Lavandula officinalis, Lobelia erinus, Tagetes patula, Verbena $\times$ hybrida i Zinnia elegans.

Klijavost većine ispitivanih tradicionalnih cvjetnih vrsta bila je ispod $50 \%$, dok je kod komercijalnih cvjetnih vrsta bila nešto viša. Najčešće bolesti na sjemenu su: Alternaria alternata, Fusarium spp. $i$ Verticillium sp., a zaraze ovim bolestima su na nekim uzorcima iznad $40 \%$. Nicanje u kontejnerima loše je kod uzoraka koji imaju nisku energiju klijanja. Boje cvjetova različite su od boja na vrećicama sjemena.
\end{abstract}


Dijana Horvat i sur.: Kvaliteta sjemena tradicijskih

cvjetnih vrsta za amaterski uzgoj

Loša kvaliteta sjemena, loše nicanje u kontejnerima, nepodudarnost boje cvjetova i visine biljaka s navodima na pakiranju glavni su uzroci nestajanja tradicijskih cvjetnih vrsta. Vrtlari amateri sjeme uglavnom kupuju u maloprodaji no zbog loše kvalitete odustaju od sjetve i uzgoja tradicijskih cvjetnih vrsta. Nestajanjem tradicijskih cvjetnih vrsta nestaju i tradicijski seoski vrtovi.

Ključne riječi: tradicijske cvjetne vrste, energija i klijavost sjemena, zdravstveno stanje sjemena

\section{UVOD}

Tradicijska seoska okućnica nipošto nije izdvojena od gospodarske funkcije seoskog imanja. Uklopljena je u neposredan kulturni krajobraz jednako kao i stambeni i gospodarski objekti na parceli. Kulturni krajobrazi su rezultat međudjelovanja ljudi i prirode (Stanner i Bourdeau, 1995; UNESCO,1997; Vijeće Europe, 2000), svjedoci prošlog i sadašnjeg odnosa između ljudi i okoliša. Krajobrazi su dio europskog kulturnog nasljeđa i ključna sastavnica lokalnog, regionalnog i nacionalnog identiteta, kao što ga prepoznaje Europska Konvencija o Krajobrazu (Vijeće Europe, 2000; prema Calvo-Iglesiasi sur., 2006). Socioekonomske i društvene promjene ostavljaju tragove i u okolišu. Izmjene radne i obrazovne strukture stanovništva te ekonomski uvjeti proizvodnje dobara indirektno mijenjaju krajobraz nestankom tradicionalnih načina obrade tla, intezifikacijom poljoprivrede, širenjem gradskog načina života $u$ ruralne prostore ili pak napuštanjem određenih prostora i njihovog prepuštanja sekundarnoj sukcesiji (Lončar i Cvitanović, 2012).

Seoski vrtovi oduvijek su bili integralni dio cjelokupnog proizvodnog sustava seoskog gospodarstva. Uglavnom se radi o malim površinama, koje većinom održavaju žene, a proizvodnja na njima nije prvenstveno usmjerena prema tržištu (Vogl i VoglLukasser, 2003). Ruralni karakter vrtova uz kuću odaje mješavina ugodnog i korisnog pa uz povrće, voće i ljekovite trave raste cvijeće i ukrasno grmlje (Kapović, 2005). Uvjetovani su klimom i reljefom pojedinog područja tako da se razlikuju po geografskim regijama (Židovec i sur., 2006). Na području Republike Hrvatske uočljivi su dijelovi različitih prirodno-geografskih cjelina (Panonska nizina, Dinaridi, Sredozemlje) te se na relativno malom prostoru smjenjuju različiti krajolici, što je utjecalo na stil života i tip gospodarstva gotovo jednako kao i društveno kulturni običaji susjednih zemalja (Filipčić i Stiperski, 2002, prema Matulec, 2003).

Posljednjih desetljeća 20. stoljeća velik dio stanovništva prestaje se intenzivno baviti poljoprivredom i zapošljava se $u$ urbanim središtima ne mijenjajući mjesto stanovanja. To je uzrokovalo miješanje ruralnog i urbanog, što se odrazilo i na uređenje cvjetnjaka u seoskim sredinama (Plačko, 1977; Feletar, 1991; prema Matulec, 2003). Vrtovi naših baka nalikovali su malim rascvjetalim džunglama. Što bujnije, šarenije, bogatije to bolje. Uz vanjski i unutarnji rub ograde, među gredicama s povrćem 
Dijana Horvat i sur.: Kvaliteta sjemena tradicijskih

cvjetnih vrsta za amaterski uzgoj

sadilo se i sijalo cvijeće. Na ogradu su se oslanjale visoke i krhke kosmeje, vrtni suncokreti, cinije raskošnih boja, jesenski asteri i noćurci. Lijepa kata, turski karanfil, sljez, vrtni mak, dalija, božur, pakujac i šeboj izmjenjivali su se u raskošnoj cvatnji. Na gredicama među povrćem, cvali su ljekoviti dragoljubi i neveni te za zdravlje povrtnica važne kadifice (Papeš-Moko s, 1995).

Danas, takve vrtove možemo vidjeti samo na starim slikama i u zabačenim seoskim sredinama gdje urbanizacija još nije stigla ostaviti svoj trag. Vrtlari amateri posljednjih godina pokušavaju obnoviti tradicijske seoske vrtove no rezultat su obično pravilne cvjetne gredice bogate cvjetnim vrstama koje susrećemo u ponudi velikih trgovačkih lanaca, u maloprodajama i na tržnicama.

Tradicijske cvjetne vrste polako nestaju a jedan od mogućih uzroka je loša kvaliteta sjemena. Ponuda tradicijskih cvjetnih vrsta bazirana je na uvoznom sjemenu čija kvaliteta prema Pravilniku o stavljanju na tržište poljoprivrednog reprodukcijskog materijala ukrasnog bilja NN 129/07 ne podliježe nikakvoj kontroli.

Vrtlari amateri sjeme uglavnom kupuju u maloprodajama no zbog loše kvalitete često odustaju od sjetve i uzgoja tradicijskih cvjetnih vrsta. Sjeme je loše klijavosti, visine biljaka, oblici i boje cvjetova često se ne podudaraju sa slikama na ambalaži sjemena. Nestankom tradicijskih cvjetnih vrsta, nestat će i tradicijski seoski vrtovi.

\section{MATERIJAL I METODE ISTRAŽIVANJA}

Uzorci sjemena uzorkovani su prema metodi slučajnog odabira. Od svakog ispitivanog uzorka uzorkovano je pet vrećica sjemena kod sjemena čija pakiranja su bila iznad 5 g i 10 vrećica kod sjemena čija pakiranja su bila do $5 \mathrm{~g}$. Uzorkovano je sjeme od četiri najveća uvoznika sjemena cvjetnih vrsta. U laboratoriju za ispitivanje kvalitete poljoprivrednog reprodukcijskog materijala na Visokom gospodarskom učilištu u Križevcima ispitana je energija klijanja, klijavost i zdravstveno stanje po jednog uzorka vrsta Ageratum houstonianum, Impatiens walleriana, Lavandula officinalis, Lobelia erinus i Verbena $\times$ hybrida; po dva uzorka vrsta Cosmos bipinatusi Tagetes patula, te po tri uzorka vrsta Calistephus chinnensis, Dahlia pinata i Zinnia elegans. Analize kvalitete sjemena provedene su na ukupno 18 uzoraka sjemena cvjetnih vrsta. Od uzorkovanih primarnih uzoraka napravljen je zbirni uzorak iz kojeg su prilagođenom metodom prepolavljanja (Pravilnik o metodama uzorkovanja i ispitivanja kvalitete sjemena NN 99/08) napravljeni radni uzorci koji su analizirani.

Postupci ispitivanja energije i klijavosti sjemena cvjetnih vrsta nisu navedeni $u$ Pravilniku o metodama uzorkovanja i ispitivanja kvalitete sjemena (NN 99/08), te su provedeni u skladu sa ISTA međunarodnim metodama ispitivanja energije i klijavosti sjemena (International Rules for Seedtesting 2011, Chapter 5; Germination 5-70). Energija i klijavost sjemena ispitivani su u komori za naklijavanje uz propisani predtretman, temperaturu i broj dana za određivanje energije i klijavosti (Tablica 1.) 
Primijenjena je propisana metoda na filter papiru; sjeme je stavljeno u petrijeve posudice na sloj navlaženog filter papira, pravilno raspoređeno. Energija i klijavost sjemena ispitivane su u četiri ponavljanja sa po 100 sjemenki, a klijavost svakog uzorka izražena je kao aritmetička sredina svih proba u \%. Zdravstveno stanje sjemena ispitano je metodom s izmrzavanjem (Pravilniku metodama uzorkovanja i ispitivanja kvalitete sjemena NN 99/08). Ispitivanje je provedeno u komori za ispitivanje zdravstvenog stanja sjemena na temperaturi $20^{\circ} \mathrm{C}$, uz osvjetljene NUV lampama 12 sati. Sjeme je stavljeno u petrijeve posudice na dvostruki sloj filter papira navlaženog destiliranom vodom. Ispitivanje je provedeno $\mathrm{u}$ četiri probe sa po 50 sjemenki. Metoda $\mathrm{s}$ izmrzavanjem modificirana je metoda na filter papiru, sjeme u petrijevim posudicama stavlja se na 24 sata u komoru za ispitivanje zdravstvenog stanja, nakon toga 24 sata u ledenicu na temperaturu od $-25^{\circ} \mathrm{C}$. Nakon perioda izmrzavanja premješta se u komoru za ispitivanje zdravstvenog stanja sjemena na temperaturu $20^{\circ} \mathrm{C}$ do isteka vremena

Tablica 1. Metode ispitivanja energije i klijavosti sjemena

Table 1 Methods of testing seed vigour and germination

\begin{tabular}{|c|c|c|}
\hline $\begin{array}{l}\text { Cvjetna vrsta } \\
\text { Species of flower }\end{array}$ & $\begin{array}{c}\text { Broj } \\
\text { uzoraka } \\
\text { Number } \\
\text { of } \\
\text { samples }\end{array}$ & $\begin{array}{l}\text { Metoda ispitivanja energije klijanja i klijavosti } \\
\text { Testing methods of seed vigour and germination }\end{array}$ \\
\hline $\begin{array}{l}\text { Ageratum hosutonianum } \\
\text { Miller }\end{array}$ & 1 & $\mathrm{NF}^{*}, 5-14$ dana,temp. $20^{\circ} \mathrm{C}$ \\
\hline $\begin{array}{l}\text { Calistephus chinensis ( L.) } \\
\text { Ness }\end{array}$ & 3 & $\mathrm{NF}^{*}, 7-14$ dana, temp. $20^{\circ} \mathrm{C}$ \\
\hline Cosmos bipinatus Cav. & 2 & $\mathrm{NF}^{*}, 5-14$ dana,temp. $20^{\circ} \mathrm{C}, \mathrm{PH}^{* *}, \mathrm{~S} * * *, \mathrm{KNO}_{3} * * * *$ \\
\hline Dahlia pinata Cav. & 3 & $\mathrm{NF}^{*}, 7-21$ dan, temp. $20^{\circ} \mathrm{C}, \mathrm{PH}^{* *}$ \\
\hline Impatiens walleriana Hook. f. & 1 & $\mathrm{NF}^{*}, 7-21 \mathrm{dan}$, temp. $20^{\circ} \mathrm{C}, \mathrm{PH}^{* *}, \mathrm{KNO}_{3}{ }^{* * * *}$ \\
\hline Lavandula officinalis Mill. & 1 & $\mathrm{NF}^{*}, 10-21$ dan,temp. $20^{\circ} \mathrm{C}, \mathrm{PH}^{* *}$ \\
\hline Lobelia erenis L. & 1 & $\mathrm{NF}^{*}, 14-21$ dan,temp. $20^{\circ} \mathrm{C}, \mathrm{PH}^{* *}, \mathrm{KNO}_{3} * * * *$ \\
\hline Tagetes patula L. & 2 & $\mathrm{NF}^{*}, 5-14$ dana,temp. $20^{\circ} \mathrm{C}, \mathrm{S} * * *$ \\
\hline Verbrena $\times$ hybrida Voss & 1 & $\mathrm{NF}^{*}, 10-28$ dana,temp. $20^{\circ} \mathrm{C}, \mathrm{PH}^{*} *, \mathrm{KNO}_{3} * * * *$ \\
\hline Zinia elegans Jacq. & 3 & $\mathrm{NF}^{*}, 5-10$ dana,temp. $20^{\circ} \mathrm{C}, \mathrm{S} * * *, \mathrm{PH}^{* *}$ \\
\hline \multicolumn{3}{|l|}{$\begin{aligned} * \mathrm{NF} & \text { - ispitivanje na filter papiru } \\
& \text { - test method on filter paper }\end{aligned}$} \\
\hline \multicolumn{3}{|c|}{$\begin{aligned} \text { ** } \mathrm{PH} & \text { - prethodno hlađenje na temperaturi } 5^{\circ} \mathrm{C} \text { sedam dana } \\
& \text { - pre-cooling at } 5{ }^{\circ} \mathrm{C} \text { for seven days }\end{aligned}$} \\
\hline \multicolumn{3}{|c|}{$\begin{array}{l}\text { *** } \mathrm{S} \text { - svijetlo u komori za naklijavanje } 24 \text { sata tijekom cijelog ispitivanja } \\
\text { - light in the germination chamber for } 24 \text { hours during the all period of testing } \\
\text { ***** } \mathrm{KNO}_{3} \text { - tretiranje podloge sa } 2 \% \text { otopinom kalijevog nitrata } \\
\text { pad treatment with } 2 \% \text { potassium nitrate solution }\end{array}$} \\
\hline
\end{tabular}


Dijana Horvat i sur.: Kvaliteta sjemena tradicijskih cvjetnih vrsta za amaterski uzgoj

predviđenog za ispitivanje. Nakon inkubacije od 10 dana određivana je prisutnost patogena na sjemenu pregledom pod steromikroskopom (određivanje patogena na osnovi izgleda konidiofora i smještaja konidija na konidioforu: Alternaria spp.). Determinacija patogena na osnovu izgleda konidija određivana je pod mikroskopom. Pregledavano je sve sjeme postavljeno na inkubaciju, a \% zaraze izračunat je kao aritmetička sredina zaraze svih četiriju proba pojedinim patogenom.

$\mathrm{Na}$ osam uzoraka cvjetnih vrsta: Ageratum houstonianum, Dahlia - mini, Impatiens wallerina, Lavandula officinalis, Lobelia erinus, Tagetes patula, Verbena $\times$ hybrida i Zinnia elegans ispitivano je nicanje u kontejnerima u zatvorenom prostoru i rast u cvjetnim lončićima na otvorenom. Sjeme je sijano u kontejnere od 120 sadnih mjesta napunjene supstratom Brill i to $\mathrm{u}$ svaku jerupu posijana po jedna sjemenka. Kontejneri sa sjemenom smješteni su $u$ plastenik na stolove za uzgoj presadnica $u$ kontrolirane uvjete konstantne temperature $25^{\circ} \mathrm{C}$ i $75 \%$ vlage zraka.

Nakon nicanja, u fazi četiri prava lista presadnice su presađivane u cvjetne lončiće promjera $18 \mathrm{~cm}$. Od vrsta Ageratum houstonianum, Dahlia - mini, Lobelia erinusi Verbena $\times$ hybrida presađeno je 50 biljaka. Zbog lošeg nicanja od vrste Impatiens wallerina presađeno je 18 biljaka, a od vrste Tagetes patula 24 biljke.

U cvatnji su uspoređivane boje cvjetova sa bojama na ambalaži sjemena, određivan je broj boja cvjetova i podudarnost nijansi, te pripadnost navedenoj cvjetnoj vrsti.

\section{REZULTATI ISTRAŽIVANJA}

Energija i klijavost ispitivanih cvjetnih vrsta navedeni su u Tablici 2. Iz podataka je vidljivo da je energija klijanja kod 10 ispitivanih uzoraka $0 \%$, što je znak starog ili sjemena bez minimalnih parametara kvalitete.

Klijavost pet uzoraka ispitivanih cvjetnih vrsta je iznad 50\%. Prema Pravilniku o temeljnim zahtjevima kakvoće, načinu ispitivanja, pakiranju i deklariranju sjemena poljoprivrednog bilja NN 4/05, minimalna propisana klijavost sjemena cvjetnih vrsta bila je 50\%, dok prema važećem Pravilniku o stavljanju na tržište poljoprivrednog reprodukcijskog materijala ukrasnog bilja NN 127/09 minimalna klijavost sjemena cvjetnih vrsta nije propisana.

Od ispitivanih uzoraka cvjetnih vrsta $72 \%$ uzoraka ima klijavost ispod $50 \%$ (Grafikon 1.). 
Dijana Horvat i sur.: Kvaliteta sjemena tradicijskih cvjetnih vrsta za amaterski uzgoj

Tablica 2. Energija klijanja i klijavost sjemena ispitivanih uzoraka Table 2 Seed vigour and germination of the tested samples

\begin{tabular}{|c|c|c|}
\hline $\begin{array}{c}\text { Cvjetna vrsta } \\
\text { Species of flower }\end{array}$ & $\begin{array}{l}\text { Energija klijanja } \\
\text { Seed vigour }(\%)\end{array}$ & $\begin{array}{c}\text { Klijavost } \\
\text { Germination }(\%)\end{array}$ \\
\hline Ageratum hosutonianum Miller & 96 & 99 \\
\hline Calistephus chinensis ( L.) Ness $1 *$ & 0 & 0 \\
\hline Calistephus chinensis ( L.) Ness $2 *$ & 0 & 42 \\
\hline Calistephus chinensis ( L.) Ness $3 *$ & 0 & 36 \\
\hline Cosmos bipinatus Cav. $1 *$ & 0 & 0 \\
\hline Cosmos bipinatus Cav. $2 *$ & 0 & 22 \\
\hline Dahlia pinata Cav. $1 *$ & 40 & 52 \\
\hline Dahlia pinata Cav. $2 *$ & 26 & 32 \\
\hline Dahlia pinata Cav. $3 *$ & 20 & 18 \\
\hline Impatiens walleriana Hook.f. & 0 & 18 \\
\hline Lavandula officinalis Mill. & 0 & 0 \\
\hline Lobelia erenis L. & 70 & 70 \\
\hline Tagetes patula L. $1 *$ & 26 & 40 \\
\hline Tagetes patula L. $2 *$ & 40 & 52 \\
\hline Verbrena $\times$ hybrida Voss & 42 & 60 \\
\hline Zinia elegans Jacq. $1 *$ & 0 & 0 \\
\hline Zinia elegans Jacq. $2 *$ & 0 & 20 \\
\hline Zinia elegans Jacq. $3^{*}$ & 12 & 18 \\
\hline
\end{tabular}

* broj uzorka cvjetne vrste zastupljene u ispitivanju

the number offlower species represented in the test

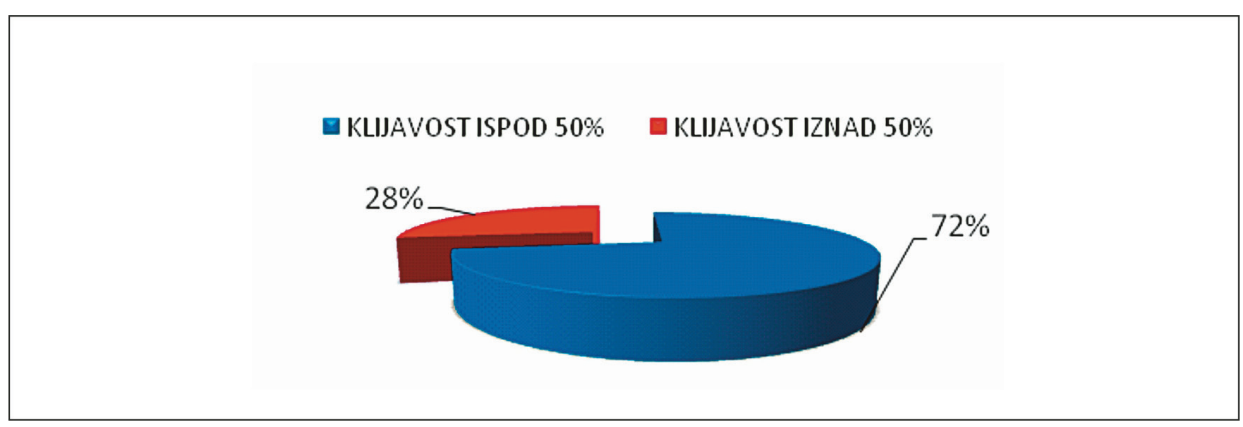

Grafikon 1. Klijavost ispitivanih uzoraka

Figures 1 Germination of tested samples

Zdravstveno stanje sjemena cvjetnih vrsta ne podliježe zakonskim regulativama. Nakon provedenih analiza zdravstvenog stanja sjemena zabrinjavajuća je činjenica da su svi ispitivani uzorci zaraženi čađavicom Alternaria alternata, koja je pokazatelj dugog stajanja sjemena a u vegetaciji izaziva simptome čađavosti na cvatu kod svih ispitivanih cvjetnih vrsta. Postotak zaraze sjemena ovom gljivičnom bolesti kretao se do $43 \%$ 
Dijana Horvat i sur.: Kvaliteta sjemena tradicijskih cvjetnih vrsta za amaterski uzgoj

(Grafikon 2.). Na 11 uzoraka utvrđena je zaraza sa Fusarium spp., a zaraza se kretala do $18 \%$. Mikroskopskim pregledom micelija i determinacijom na osnovu izgleda konidija najčešći patogen iz roda Fusarium na ispitivanim uzorcima bio je Fusarium oxysporum. Rod Fusarium predstavljaju polifagne gljive koje mogu uzrokovati polijeganje i propadanje rasada, te u vegetaciji uništiti biljku i cvijet. Zaraza gljivicom Verticillium spp. utvrđena je na sedam uzoraka, a kretala se do 5\% (Grafikon 2.).

Loše nicanje bilo je kod vrsta kod kojih je bila niska energija i klijavost sjemena. Od osam ispitivanih uzorka tri uzorka imala su postotak nicanja iznad $50 \%$ (Tablica 3). Tagetes patula i Zinia elegans imale su postotak nicanja u kontejnerima $20 \%$ niži od klijavosti sjemena. To su vrste koje bolje niču kod sjetve širom no za takav način uzgoja potrebno je sjeme visoke klijavosti zbog kasnijeg prorjeđivanja biljaka.

Ispitivane cvjetne vrste pripadale su vrsti navedenoj na ambalaži. Ageratum hosutonianum i Lobelia erinus cvale su u plavoj boji. Kod Dahlia pinata boje cvatova bile su bijela, svijetlo crvena i boja višnje, dok su na ambalaži osim navedenih boja bili cvatovi roza i tamnoljubičaste boje. Verbena $\times$ hybrida cvala je u bijeloj, ljubičastoj, roza i narančastocrvenoj boji. Identične boje cvjetova bile su i na ambalaži sjemena. Tagetes patula cvala je u dvije boje što se poklapalo s bojama na ambalažiali visina biljaka bila je različita. Biljke žutog cvata bile su izrazito više od biljaka narančaste boje (Slika 1.).

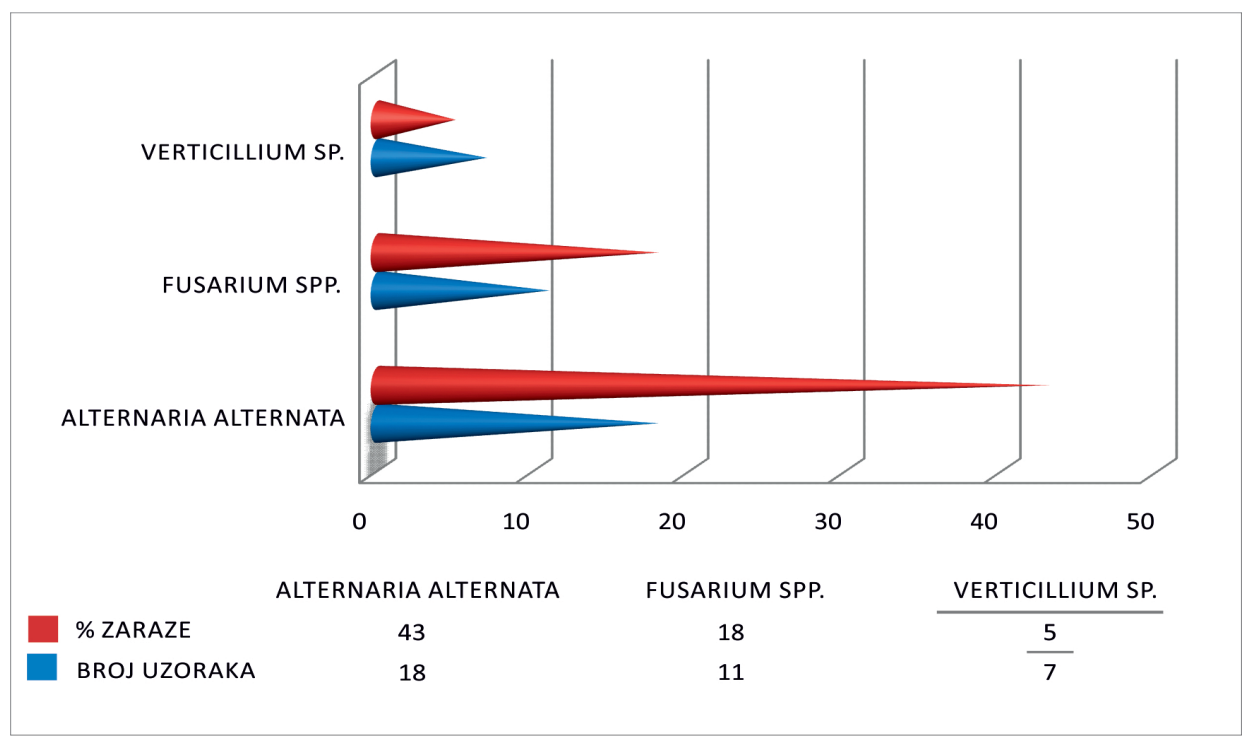

Grafikon 2. Zdravstvena ispravnost ispitivanih uzoraka sjemena

Figures 2 Diseases on the tested samples seeds 
Dijana Horvat i sur.: Kvaliteta sjemena tradicijskih cvjetnih vrsta za amaterski uzgoj

Tablica 3. Nicanje biljaka u kontejnerima

Table 3 Emerging of plants in the containers

\begin{tabular}{lc}
\hline \multicolumn{1}{c}{ CVJETNE VRSTE } & \% NICANJA \\
\hline Ageratum hosutonianum Miller & 90 \\
\hline Dahlia pinata Cav. 1 & 60 \\
\hline Impatiens walleriana Hook.f & 15 \\
\hline Lavandula officinalis Mill. & 0 \\
\hline Lobeliaerenis L. & 72 \\
\hline Verbrena $\times$ hybrida Voss & 45 \\
\hline Tagete spatula L. 1 & 20 \\
\hline Zinia elegans Jacq. 3 & 0 \\
\hline
\end{tabular}

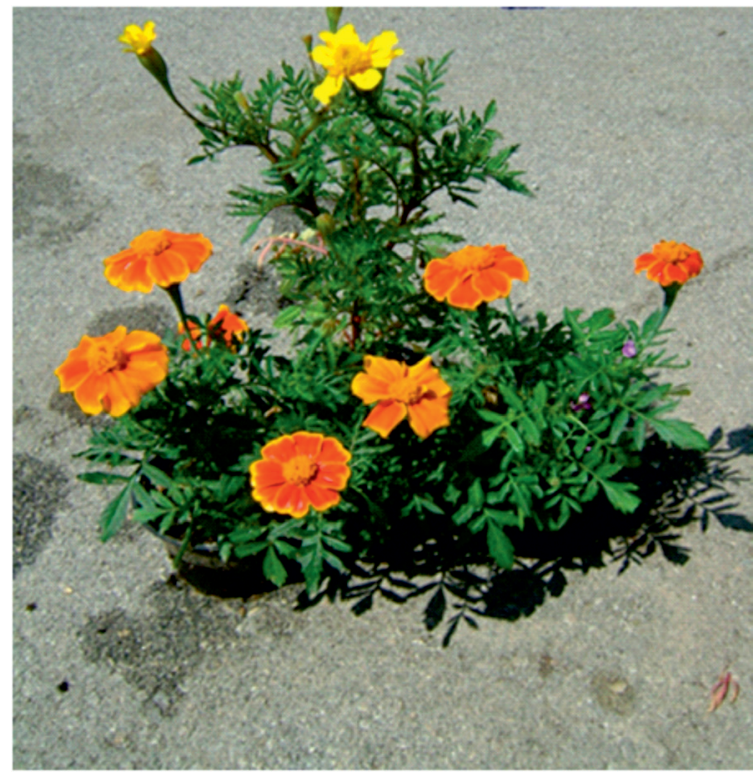

Slika 1. Razlike u visini biljka kod uzorka Tagete spatula L. 1

Photo 1 The differences of plant height on the samples of Tagetemms patula L. 1

\section{ZAKLJUČAK}

Hrvatska svojim položajem i klimom pruža idealne uvjete za uzgoj sjemena. Dugogodišnja tradicija uzgoja sjemena cvjetnih vrsta nestala je, a s njom nestaju i tradicijske cvjetne vrste. Ponuda sjemena je velika, no sjeme je loše kvalitete i sortnosti. 
Dijana Horvat i sur.: Kvaliteta sjemena tradicijskih

cvjetnih vrsta za amaterski uzgoj

Provedeno ispitivanje pokazuje da je klijavost sjemena tradicijskih cvjetnih vrsta ispod $50 \%$, a kod nekih vrsta i $0 \%$. Vrtlari amateri sjeme nabavljaju u maloprodaji, a sva ponuda temelji se na uvozu. Razočarani kvalitetom sjemena vrtlari amateri kupuju gotove presadnice komercijalnih cvjetnih vrsta kod profesionalnih proizvođača cvijeća u velikim trgovačkim lancima i u maloprodaji. Kvaliteta sjemena svih biljnih vrsta koje susrećemo na tržištu regulirana je zakonskim propisima osim kod cvjetnih vrsta. Kontrola kvalitete sjemena na tržištu provodi se u vidu inspekcijskog nadzora nad sjemenom svih biljnih vrsta osim cvijeća. Reguliranjem zakonskih propisa i uvođenjem minimalne klijavosti za sjeme cvjetnih vrsta utjecalo bi se na kvalitetu sjemena, a ponudom kvalitetnog i klijavog sjemena proširio bi se uzgoj tradicionalnih cvjetnih vrsta kod vrtlara amatera.

Posljednjih godina u Hrvatskoj sve se više pažnje posvećuje očuvanju kulturne baštine, tradicije i običaja. Razvojem ruralnog turizma budi se i svijest o važnosti tradicionalnih seoskih vrtova, no bez tradicijskih cvjetnih vrsta nema ni tradicijskih vrtova.

\title{
SEED QUALITY OF TRADITIONAL FLOWER SPECIES FOR HOBBY CULTIVATION
}

\begin{abstract}
SUMMARY
Traditional flower species used to be one of the most important parts of traditional rural gardens, along with vegetables and aromatic and medicinal herbs. During the $20^{\text {th }}$ century, as the way of life in rural populations began to change, traditional rural gardens and traditional flower species started to die out. Today, amateur gardeners are trying to renew traditional rural gardens, what often results in gardens filled with flower species commonly found in large chain stores, retail stores and markets.

Poor seed quality might be the cause of disappearance of traditional flower species. Flower seed isn't produced in Croatia, so the seed supply is based only on the import of seed, whose quality parameters aren't legally determined. 18 samples of ten flower species imported 2011/2012: Ageratum hosutonianum, Calistephu schinensis, Cosmos bipinatus, Dahlia pinata, Impatiens walleriana, Lavandula officinalis, Lobelia erenis, Tagetes patula, Verbrena $\times$ hybrida, Zinia elegans have been tested on their seed vigour, germination and seed health by the ISTA international testing methods. Besides the traditional flower species, a few commercial flower species have also been included in the tested sample.

Emergence rate in containers, growth in flower pots and inflorescence colour have been tested on eight flower species: Ageratum hosutonianum,
\end{abstract}


Dahlia - mini, Impatiens wallerina, Lavandula officinalis, Lobelia erinus, Tagetes patula, Verbena $\times$ hybrida and Zinnia elegans.

Germination of the majority of tested flower species was under $50 \%$, and in the commercial flower species it was somewhat higher. The most common seed diseases are: Alternaria alternata, Fusarium spp. and Verticillium sp., and on some samples the infections with these diseases were over $40 \%$. Emergence rate in containers is poor on samples with low seed vigour. Inflorescence colours of the flowers are different than the ones on the seed packages.

Bad seed quality, poor emergence rate in containers, and incompatibility of inflorescence colour and plant height with the certified ones are the main causes for the disappearance of the traditional flower species. Amateur gardeners mostly buy their seeds in retail, but due to poor quality they give up on planting and cultivating traditional flower species. With the disappearance of traditional flower species, traditional rural gardens are also dying out. health.

Key words: traditional flower species, seed vigour, germination, seed

\section{LITERATURA - REFERENCES}

1. Calvo-Iglesias, S.M., Crecesnte-Maseda, R.,Fra-Paleo, U., (2006) Exploring farmer's knowledge as a source of information on past and present cultural landscapes A case study from NW Spain. Landscapeand Urban Planning 78: 334-343

2. Feletar, D. (1991) Promjene u prostornom rasporedu stanovništva Podravine. Podravski zbornik 1991. Muzej grada Koprivnice, Bjelovar: 51-62

3. Filipčić, A., Stiperski, Z., (2002) Republika Hrvatska. U Thomas L. (ur.) Školski atlas: 2640

4. Kapović, N., (2005). Izvorno zelenilo u službi očuvanja ruralnog ambijenta na primjeru Konavala. Agronomski glasnik 2-4: 209-223

5. Lončar, J., Cvit an ović, M. (2012) (Post)socijalizam i okoliš: promjena kulturnog krajobraza Pridravske nizine Osijeka u posljednjih pedest godina. Sociologija i prostor 50-194(3): 327-343

6. Matulec, Lj., (2003) Taksonomska analiza hortikulturne flore seoskih cvjetnjaka središnjeg dijela Bilogorske Podravine. Agronomski glasnik 6: 271-290

7. Papeš-Mokos, B., (1995) Starinsko cvijeće i ljekovito bilje. Hrvatski centar Znanje za okoliš, Zagreb.

8. Plačk o, Lj., (1977) Podravci na privremenom radu u inozemstvu. Podravski zbornik 1977. Muzej grada Koprivnice, Čakovec: 195-202

9. Stanner, D., Bourdeau, P. (ur.) (1995) Landscapes. Chapter 8. Europe's Environment, The Dobri's European Environment Agency, Copenhagen.

10. UNESCO (1997) Operational Guidelines for the Implementation of the World Heritage Convention, UNESCO, Paris

11. Vijeće Europe (2000) European Landscape Convention. ETS No. 176 Council of Europe Publishing Division, Strasbourg. 
12. Vogl, C.R., Vog1-Lukasser, B., (2003). Tradition, Dynamics and Sustain ability of Plant Species Composition and Management in Homegardens on Organic and Non-Organic Small Scale Farms in Alpine Eastern Tyrol, Austria. Biological Agriculture and Horticulture 21, 349-366

13. Židovec, V., Vršek, I., Aničić, B., Grzunov, S. (2006). Tradicijski seoski vrtovi Sjeverozapadne Hrvatske. Sjemenarstvo 23(3): 273-283.

\author{
Adresa autora - Authors' addresses: \\ Dijana Horvat, dipl.ing. \\ Samir Marciuš \\ Visoko gospodarsko učilište u Križevcima \\ E-mail : dhorvat@vguk.hr \\ Prof. dr. sc. Vesna Židovec \\ Agronomski fakultet Sveučilišta u Zagrebu \\ Svetošimunska 25 \\ 10000 Zagreb
}


